\title{
Reducing the carbon emission in shipping industry- Application and development of LNG fueled ships in China
}

\author{
Mingyu TIAN ${ }^{1, a}$, Hao CAl ${ }^{2,3, b}$ and Hongbing $\mathrm{ZOU}^{4, c^{*}}$ \\ ${ }^{1}$ School of Energy \& Power Engineering, Wuhan University of Technology, Wuhan, China \\ ${ }^{2}$ School of Computer Science \& Technology, Wuhan University of Technology, Wuhan, China \\ ${ }^{3}$ Intelligent Transportation Systems Research Center, Wuhan University of Technology, Wuhan, \\ China \\ ${ }^{4}$ School of Navigation, Wuhan University of Technology, Wuhan, China \\ a tianmingyu@whut.edu.cn, b caihao@whut.edu.cn, c bhzsin@163.com
}

\begin{abstract}
Keywords: LNG, green energy, shipping industry, dual fuel engine.
Abstract: Nowadays, a variety of shipping-induced environmental problems and increasingly rigid emission restrictions have drawn more attention to an emerging marine fuel-liquefied natural gas (LNG). Although a number of theoretical research and experiment of the usage of LNG onboard have been successfully conducted, its application in the shipping industry is not widely seen. This paper comprehensively introduced the development of LNG fueled ships in China from the aspects of its superiorities, industrial test, and current status of the application. A case of the first officially certificated diesel-LNG dual fueled ship in inland waterways of China -"Hong Ri 166" - was introduced by using the empirical data obtained from field studies. This paper offers some insight on the prospects of the application of LNG in the Chinese shipping industry and provides a reference for decision-makers on how to facilitate the development of LNG fueled ship in a safe and efficient way.
\end{abstract}

\section{Introduction}

Inland waterways in China such as the Yangtze River are suffering from various kinds of problems including serious environmental pollution, outdated marine technology and ship equipment, and high energy consumption. A recent statistics [1] shows that about 1.2 billion barrels of diesel fuel are consumed by the global shipping industry every year, resulting in the emission of a large amount of exhaust gas. International shipping was responsible for approximately $10-20 \%$ of the total emission of nitrogen oxides $\left(\mathrm{NO}_{x}\right), 4 \%-8 \%$ of that of sulfur oxides $\left(\mathrm{SO}_{x}\right)$, and $6 \%$ of that of carbon dioxide $\left(\mathrm{CO}_{2}\right)$. Therefore, the mitigation of environmental impact and reduction of traditional fuel consumption are urgently required, while gaining the benefits from the shipping industry. A research report by the Det Norske Veritas (DNV) revealed that, among the 25 measures under investigation, liquefied natural gas (LNG) was confirmed to be the most superior one in terms of both the influence on emission reduction and cost-effectiveness [2]. Thus, to facilitate the development of LNG fueled vessels is of great significance to the energy conservation and emission reduction of inland shipping in China.

LNG is mainly composed of methane $\left(\mathrm{CH}_{4}\right)$, with some mixture of ethane $\left(\mathrm{C}_{2} \mathrm{H}_{6}\right)$. According to the List of Dangerous Goods (GB12668-2005) published by the Standardization Administration of China (SAC), LNG was numbered 1972 (in liquid state) of the United Nations (UN) Number. It is odorless, colorless, non-toxic, and non-corrosive [3]. However, hazards of LNG include flammability after vaporization into a gaseous state, freezing and asphyxia. LNG takes up one 625th the volume of natural gas in the gaseous state (at standard conditions for temperature and pressure), and about one 2nd the weight of water of the same volume [4].

Natural gas is usually converted into LNG for ease and safety of non-pressurized storage or transport. The liquefaction process involves removal of certain components, such as dust, acid gases, helium, water, and heavy hydrocarbons, which could cause difficulty downstream. The natural gas is then condensed into a liquid at close to atmospheric pressure by cooling it to approximately $-162{ }^{\circ} \mathrm{C}$. LNG is recognized as one of the world's cleanest fuel due to its minimal pollution to the air after full 
combustion compared to other traditional fuel such as petroleum and gasoline. Moreover, LNG is the more cost-effective one compared to other currently widely used clean energies such as hydrogen, methanol, ethanol, and biofuels, with mature application experience.

\section{Application of LNG fueled ships in China}

Transformation of LNG fueled engine is conducted based on the existing marine diesel engines by equipping LNG gas supply systems and a diesel-LNG dual fuel injection system, through which, the operation under two modes- pure diesel fuel mode and dual fuel mode- can be realized. The transformation of single fuel diesel into LNG dual fuel power system and the partial adoption of LNG instead of diesel fuel can help to save energy and reduce emissions [5]. Not only can the newly built ships use LNG as marine fuel, but the current ship can also be modified to use the LNG/ diesel dual fuel engine. The existing ships generally apply diesel as the main fuel. When they are transformed into dual fuel ships, the main systems that need to be added include LNG storage tanks, gas processing systems, and some auxiliary systems such as ventilation systems, electronic control units (ECU), security systems, and control systems.

The research and application of the transformation of LNG fuel ships in China began in 2010. On August 2010, Hubei Xilan Natural Gas co., Ltd successfully modified the LNG power system for the ship "Wuhan Tug No.302", and launched a pilot voyage in the Wuhan section of the Yangtze River. The experiment results showed that when working under the dual fuel mode, the parameters of the modified engine are stable under different working conditions, and the performance of diesel engine is better than that when operating under pure diesel mode. The diesel engine can effectively convert the fuel in the specified speed range, and the conversion process is convenient and fast. There is a significant improvement of the diesel engine with respect to the reduction of noise and pollution under rated condition. The replacement rate of LNG can reach $66 \% \sim 80 \%$, resulting in considerable economic benefits. On September 2010, the refitted diesel-LNG dual fueled ship "Sushuhuo Cargo No.1260" loaded with 3,000 tons of sand navigated from Suqian to Huaian. The trial data showed that when operating in dual fuel mode, the $\mathrm{SO}_{x}$ emissions of the ship decreased nearly $100 \%, \mathrm{NO}_{x}$ emissions were decreased by $85 \%-85 \%$ and $\mathrm{CO}_{2}$ emissions were decreased by $15 \%-20 \%$. In addition, smoke emissions and noise are also greatly reduced, indicating the potential of bringing strong social and economic benefits [6]. On March 25, 2011, a quartet cooperation agreement on the development of the demonstration application of LNG powered ships was signed by the Chinese Petroleum Kunlun Energy Co., Ltd, CNPC Jichai Power Equipment Co, Wuhan Transportation Development Group, and Wuhan Ship Design Co., Ltd in order to facilitate its development in the inland waterways of China. On April 15, the construction of the LNG powered ships started. At present, the achievements of the new energy ship demonstration project have been simultaneously applied on eight ships in Wuhan section of the Yangtze River, Wuhu, Beijing-Hangzhou Grand Canal, and Zhu River.

Since 2010, a number of pure diesel fuel ships have been successfully transformed into diesel-LNG dual-fueled ones in China, and relevant pilot voyage has been conducted along the Beijing-Hangzhou Grand Canal and the Yangtze River route. At present, they are five existing LNG vessels, serving for Guangdong LNG project (three ships) and Fujian LNG project (two ships). Another five new orders are under construction, one for the Shanghai Yangshan LNG project, and two for the Baxin and Gaogen LNG projects, respectively. Besides, there are ten more upcoming orders including two from China National Offshore Oil Corporation (CNOOC) projects and eight from China Petrochemical Corporation (SINOPEC) projects. Along with the implementation of China's coastal LNG projects, LNG import trade has developed rapidly in China, which is expected to reach more than 60 million tons/year at the end of China's "13th five-year plan". By then, the proportion of gas consumption in China's primary energy consumption will reach at least $10 \%$, and LNG fleet in China is expected to reach a scale of 50 to 60 [7]. 


\section{Typical case of transformation of inland LNG fueled ships}

"Hong Ri 166" is a bulk carrier, which was built in 2003, with a gross tonnage of 3593.56 tons and a capacity of 2720 tons. The ship is 72.0 meters long and13.20 meters wide. The main route is Huangshi-Wuhu-Shanghai. On April 7, 2007, the modification of "Hong Ri 166" was completed. During the two-year trial operation, the ship's overall performance was stable without the occurring of any failure, and it brought good economic and social effects. After being transformed into a dual fuel ship, the ship's $\mathrm{SO}_{x}$ emissions were reduced by more than $70 \%$ and $\mathrm{NO}_{x}$ emissions were reduced by $35-40 \%$. Each replacement of one ton of diesel oil can reduce carbon emissions by 0.88 tons, and oil consumption and engine noise are also significantly reduced. In total, the fuel costs were reduced by more than $20 \%$. The "Hong Ri 166 " is the first ship to obtain a ship inspection certificate since the pilot transformation of LNG fueled ships was carried out in China. The main modifications of "Hong Ri 166" are as follows:

(1) In terms of the main propulsion system of the ship, the pure diesel is used when it is away from the terminal and LNG/diesel dual fuel is used during normal navigation condition. The dual fuel composition is $70 \%$ of LNG and $30 \%$ of diesel, and the driver of the ship changes the propulsion mode of the ship by adjusting the gas and fuel conversion buttons on the bridge, as shown in Fig. 1.

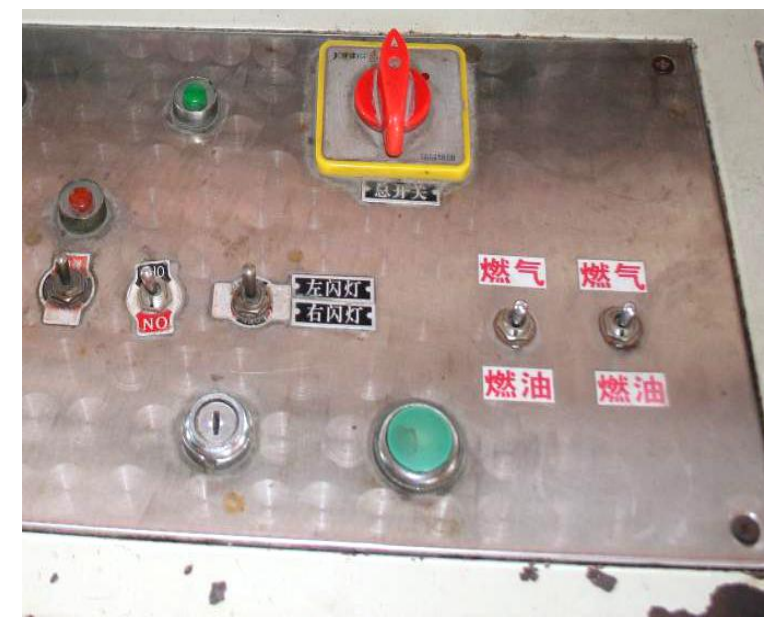

Fig.1 Gas and fuel conversion buttons on the bridge

(2) In terms of ship management, LNG / diesel dual-fuel ships are not significantly different from ordinary ships. In the gas storage tanks and cabin rooms, except for the normal fire-fighting requirements, no relevant facilities and equipment are provided separately. Attach the ship work safety instructions to the ship's bridge, especially appropriate safety measures need to be taken when the gas system breaks down, as shown in Fig.2.

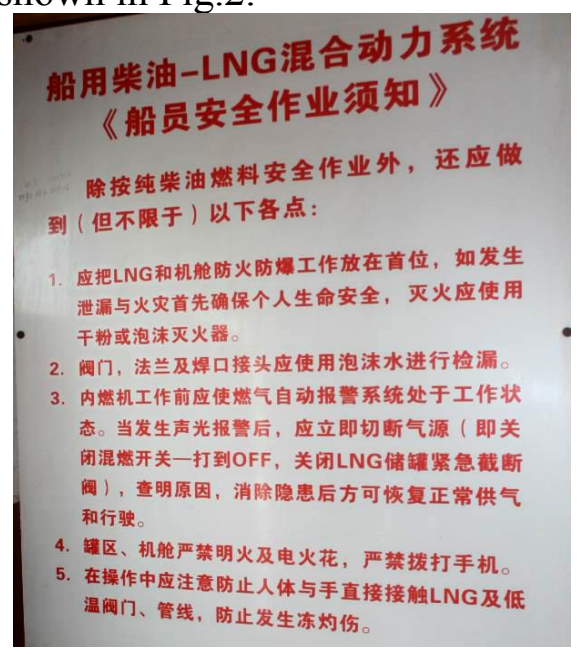

Fig.2 Safety management measures in dual fuel ship 
(3) In terms of the monitoring system, sensors are generally installed on the tank, such as pressure sensors (as shown in Fig.3), temperature sensors, liquid level sensors, and vacuum sensors; The gas detector is installed in the upper part of the nacelle. When a gas leak is detected, the low-temperature emergency shut-off valve will be actuated to close the pipeline. The gas pressure in the tank acts as the valve. When no pressure is applied, The valve closes automatically.

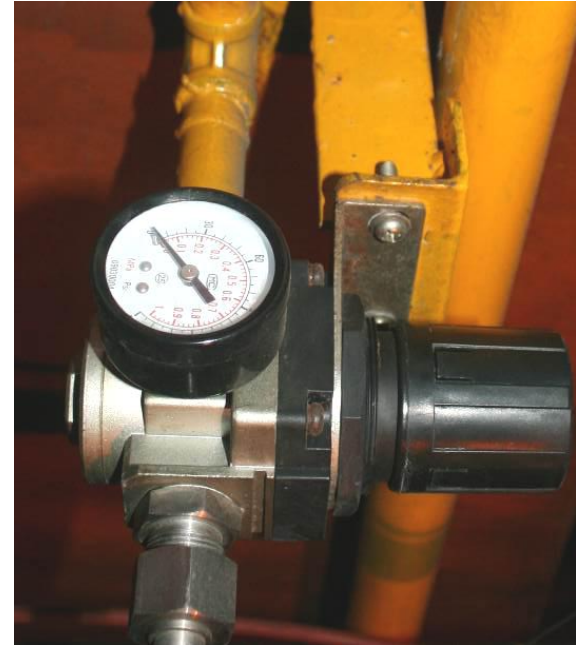

Fig.3 Pressure sensor

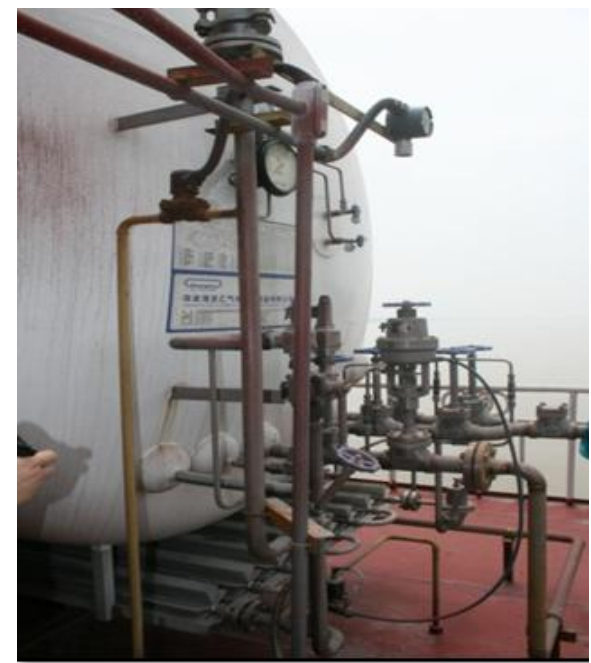

Fig.4 Pipelines of the gas tank

(4) Installation and layout of the gas tank, the ship is equipped with two-stroke six-cylinder diesel engine, rated at $441 \mathrm{kw}$. The LNG storage tank is arranged on the aft deck of a ship. A filling valve of the storage tank is divided into two channels, which respectively lead to the upper part and the lower part of the tank. The upper one is mainly used for cooling the storage tank, The lower line is filled with liquid LNG, and two sets of vaporizers are distributed below the tank. The first set of roles is to increase the pressure in the tank. The latter set is used to vaporize the liquid in the tank, as shown in Figure 4 . The gas tank is $15.8 \mathrm{~m} 3$, which can ensure the ship a voyage of about $2000 \mathrm{~km}$.

(5) In the aspect of diesel engine modification, the modification of dual-fuel engine is relatively simple, adding a fuel controller to regulate the mixing ratio of fuel and natural gas and adding natural gas pipeline into the intake pipe, as shown in Fig.5 and Fig.6.

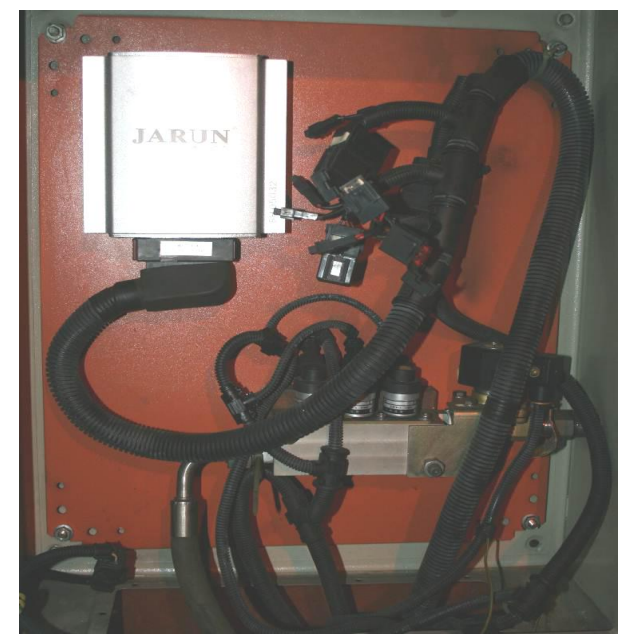

Fig.5 control panel of dual-fuel engine

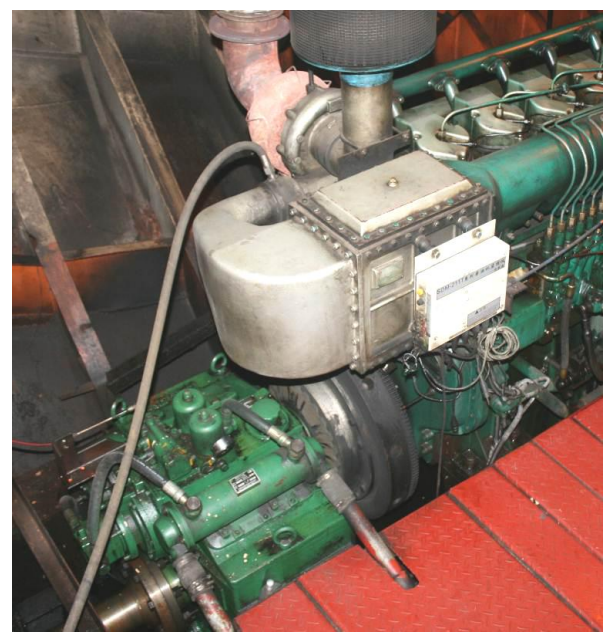

Fig.6 LNG pipeline of diesel engine 


\section{Conclusions}

Resources conservation and environmental protection are one of the main basic national policies in China. Promoting high energy-efficient LNG dual-fuel vessels is an effective measure to realize the energy conservation, emission reduction, transformation and upgrading of the water transport industry. To upgrade the ship power, reduce energy consumption and emissions and speed up the pace of clean waterway construction, are essential matters for developing green water transport and building an ecological civilization. As a marine fuel, LNG enjoys advantages of cleanness, eco-friendliness and cost efficiency. The promotion of LNG fuel-powered vessels in inland water is a prior choice to develop marine fuel recyclable economy and green economy as it not only meets the stringent national environmental protection requirements but also caters to the ship owners' urgent needs of reducing fuel cost. It calls for joint efforts of the relative governmental departments, shipping industry executives, shipping companies, related industry and research institutes to stimulate its application in practice.

\section{Acknowledgements}

This study was supported by National Science Foundation of China (NSFC) under Grant No. 5153494 and The Excellent Dissertation Cultivation Funds of Wuhan University of Technology under Grant No. 2016-YS-044.

\section{References}

[1] J.F Yuan, Y.H. Hu, G.H Jiang and J.J Tang: Technology Development and Application Status about Dual Fuel Engine. Marine Technology, Vol. 1 (2017), p.1-5.

[2] P.F. Yu: Study on Promotion of LNG-Powered Ships Based on Energy -Saving and Emission Reduction. Master Thesis of Shanghai Jiao Tong University (2015).

[3] S.S. Fu, X.P. Yan, D. Zhang and L. Xu: Marine LNG Fuel Application Strategy Analysis under Uncertainty. Journal of Wuhan University of Technology, Vol. 38 (2014), p. 1116-1120.

[4] C.P. Wan, X.P. Yan, D. Zhang and J. Shi, et al.: Emerging LNG-Fueled Ships in the Chinese Shipping Industry: A Hybrid Analysis on Its Prospects. WMU Journal of Maritime Affairs, Vol. 14 (2015), p.43-59.

[5] C.P. Wan, X.P. Yan, D. Zhang and S.S. Fu: Reliability Analysis of a Marine LNG-Diesel Dual Fuel Engine. IEEE Conference on Prognostics and System Health Management, Vol. 33 (2013), p. 811-816.

[6] D. Tu, X. Zhang, W. Wu and L. Wang: Experimental Study on Co-combustion Strategy of LNG/Diesel Dual Fuel Engine. Diesel Engine, Vol. 39 (2017), p. 22-25.

[7] H.B. Zou, B.G Zhang and L.X. Gang: Research on the adaptability of LNG Carriers in the Public Navigational Waterway in Western Shenzhen. Marine Technology, Vol. 5 (2011), p. 21-23. 